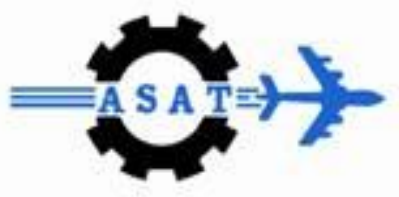

\title{
Simulating Properties of the Lower and Upper Atmosphere Using SIMULINK
}

\author{
Hatem H. Daken *
}

\begin{abstract}
A model was designed and built using The Mathworks' SIMULINK to simulate the properties of the lower and upper atmosphere. The lower atmosphere is based on the US Standard Atmosphere $1976^{1,2,3}$, which predicts the properties of the troposphere, stratosphere, mesosphere, and their inter-pauses. The upper atmosphere is based on NASA Marshall Engineering Thermosphere (MET-2) ${ }^{4}$, which predicts the properties of the ionosphere, thermosphere, and exosphere. A fairing is provided for smooth transition between the lower atmosphere, which ends at $84.852 \mathrm{~km}$, and the upper atmosphere, which begins at $90 \mathrm{~km}$. The model simulation results are in excellent agreement with NASA's MET-2 FORTRAN 77 code results.
\end{abstract}

Keywords: SIMULINK, Exterior Ballistics, US Standard Atmosphere, MET-2

\section{Introduction}

The U.S. Navy's Naval Surface Fire Support Systems (NSFS) Program Office PMS 529, which is currently reorganized into the Program Executive Office (PEO) for Integrated Warfare Systems (IWS) Code PEO IWS 3C, has developed visionary objectives for using 8" gun launched projectiles to provide ballistic missile defense (BMD) training targets for naval groups, bases, and neighboring strategic targets as part of its SBIR (Small Business Innovation Research) program.

Validation of these objectives required the evaluation of candidate projectiles, materials, and sensor technologies. Preliminary evaluation of three conceptual projectiles weighing 100, 150 , and $200 \mathrm{~kg}$, having the same muzzle exit energy of $500 \mathrm{MJ}$ (Mega Joules), resulted in predicted apogee altitudes of 351, 241, and $184 \mathrm{~km}$ (kilometers), respectively. Such altitudes are far beyond the ceiling of US Standard Atmosphere $(84.852 \mathrm{~km})$. It was therefore necessary to adopt a model that is capable of determining the atmospheric properties at altitudes above $90 \mathrm{~km}$. Atmospheric properties above this altitude are affected by:

\section{Solar Activity}

Solar electromagnetic radiation at the ultraviolet UV and EUV wavelengths changes substantially with the level of solar activity.

\footnotetext{
"Ph.D., Senior Structural Analysis Scientist/Engineer, Boeing Commercial Airplanes, The Boeing Company, Seattle, WA, USA (work was performed while working as the Principal Engineer, Defense Technology Inc., DTI, Arlington, VA, USA) hatemdaken@aol.com 


\section{Diurnal Variations}

Rotation of the Earth induces a diurnal (24-hour period) variation (diurnal tide) in thermospheric temperature and density. Due to a lag in response of the thermosphere to the EUV heat source, density maximizes around 2 p.m. local solar time at latitude approximately equal to the subsolar point. The lag decreases with decreasing altitude. Similarly, minimum density occurs between 3 and 4 a.m. local solar time at about the negative of the subsolar latitude; i.e., in the diametrically opposite hemisphere. In the lowest regions of the thermosphere $(120 \mathrm{~km}$ and below), where characteristic thermal conduction time is on the order of a day or more, the diurnal variation is not a predominant effect.

\section{Geomagnetic Activity}

Interaction of solar wind with the Earth's magnetosphere, referred to as geomagnetic activity, leads to a high-latitude heat and momentum source for the thermospheric gases. Some of this heat and momentum is convected to low latitudes. Geomagnetic activity varies, usually having one peak in activity just prior to and another just after the peak activity of the solar cycle as defined by the 10.7-cm solar radio flux. Also, larger solar cycle peaks are associated with more intense geomagnetic activity. A seasonal variation of geomagnetic activity occurs with maxima in March $( \pm 1 \mathrm{mo})$ and September $( \pm 1 \mathrm{mo})$ each year. This variation is possibly related to the tilt of the Sun's rotational axis toward the Earth.

\section{Semiannual Variations}

This variation in thermospheric density is still poorly understood, but it is believed to be a conduction mode of oscillation driven by a semiannual variation in Joule heating in the highlatitude thermosphere (as a consequence of a semiannual variation in geomagnetic activity). The variation is latitudinally independent and is modified by compositional effects. The amplitude of the variation is height dependent and variable from year to year with a primary minimum in July, primary maximum in October and secondary minimum in January, followed by a secondary maximum in April. Magnitude and altitude dependence of the semiannual oscillation vary considerably from one solar cycle to another.

\section{Seasonal/Latitudinal Variations}

The total mass density is modified further by the effects of seasonal/latitudinal density variation of the lower thermosphere below $170 \mathrm{~km}$ altitude and seasonal/latitudinal variations of helium $(\mathrm{He})$ above $500 \mathrm{~km}$. These seasonal/latitudinal variations are driven in the thermosphere by the dynamics of the lower atmosphere (mesosphere and below). Amplitude of the variation maximizes in the lower thermosphere between about 105 and $120 \mathrm{~km}$ and diminishes to zero around $200 \mathrm{~km}$. Although the temperature oscillation amplitude is quite large, corresponding density oscillation amplitude is small.

The upper atmosphere model adopted for implementation with the exterior ballistics model is NASA Marshall Engineering Thermosphere (MET-2). This model is a semi-empirical one using the static diffusion model with coefficients obtained from satellite drag analysis. It is based on the 1988 version of MET $^{5,6}$ and work done on the 1999 version ${ }^{7}$.

\section{Description of Model Key Elements}

DTI used NASA Marshall Engineering Thermosphere (MET) as a basis for developing an upper atmosphere model using MATLAB's SIMULINK version 5.0.1. The model is comprised from the following modules: 


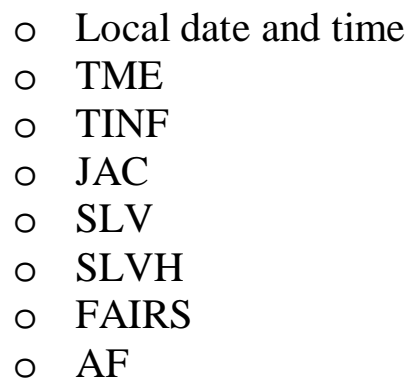

DTI's model handles all iterative DO loops using vectors, which reduces the processing load at each time step. It provides the capability to compute the variation of temperature, pressure, air mass density, speed of sound, average molecular weight, acceleration of gravity, individual specie number density, and specific heats versus altitude. The architecture and general layout of the model are illustrated in Figures 5 through 20 at the end of this article.

\section{Local date and time}

This module permits the user to choose between entering the date and time parameters manually or automatically reading them from the system's clock. In the later case a module is provided to ensure that outputs are frozen to their initial values at the start of simulation.

It outputs the year (Y), day of the year since January $1(\mathrm{~d})$, hour $(\mathrm{H})$, and minute $(\mathrm{M})$.

\section{TME}

This module computes the solar declination (SDA-R) and hour angle (SHA-R), in radians, and the day of the year, normalized by the tropical year (DY), using outputs from the local date and time plus the current longitude (LONG-D), in degrees.

\section{TINF}

This module computes the exospheric temperature (TE), using solar declination (SDA-R) and hour angle (SHA-R), the day of the year, normalized by tropical year (DY), daily $10.7-\mathrm{cm}$ solar radio flux (F10), average 10.7-cm solar radio flux over six solar rotations (F10B), 3 hourly geomagnetic Index (GI), and the geomagnetic flag (I1) to indicate whether a linear of logarithmic index is used.

\section{JAC}

This module computes the temperature (TZ), average molecular weight (EM), density (DENS), and the individual specie number density (A(i)) using the exospheric temperature (TE) and altitude (ALT). Between 90 and $105 \mathrm{~km}$ the density is calculated by integration of the barometric equation. For altitudes above $105 \mathrm{~km}$, the diffusion equation for each of the individual species $(\mathrm{O} 2, \mathrm{O}, \mathrm{N} 2, \mathrm{He}$, and $\mathrm{Ar})$ is integrated upward from the $105 \mathrm{~km}$ level. The number density for an individual species in the altitude range $90-105 \mathrm{~km}$ is calculated using a partition function based upon the sea level composition.

\section{SLV}

This module computes the logarithm of seasonal-latitudinal variation of density using the altitude (ALT), day of the year (d), and the current latitude (XLAT-R). This affects the densities between 90 and $170 \mathrm{~km}$. 


\section{SLVH}

This module computes the seasonal-latitudinal variation of the helium number density using the altitude (ALT), day of the year (d), solar declination angle (SDA-R), and the current latitude (XLAT-R). This correction is not important below $500 \mathrm{~km}$.

\section{FAIRS}

This module fairs between the region above $500 \mathrm{~km}$, which invokes the seasonal-latitudinal variation of the helium number density and the region below, which does not invoke any seasonal-latitudinal variation at all. The module is active in the altitude range $440-500 \mathrm{~km}$

\section{AF}

This module computes the individual specie number density (AF), the pressure scale height $(\mathrm{H})$, specific heat at constant pressure $(\mathrm{CP})$, specific heat at constant volume $(\mathrm{CV})$, and ratio of specific heats (GAM) at any given altitude.

Equations of the U.S. Standard Atmosphere 1976 can be found in References [1], [2], and [3]. Equations of MET-2 can be found in Reference [4].

\section{Model Initialization, Validation, and Results}

Output from the upper atmosphere module is switched on once an altitude of $90 \mathrm{~km}$ is reached. The US Standard Atmosphere is extended to $90 \mathrm{~km}$ and fairings are provided to ensure smooth transition of the atmospheric parameters from the US Standard Atmosphere to NASA's MET-2.

\section{Initialization}

Model initialization requires the following parameters to be entered manually:

o Position, longitude and latitude

o 3 hourly Geomagnetic Index (linear or logarithmic)

o Geomagnetic flag to indicate the type of index used (linear or logarithmic)

o Daily $10.7 \mathrm{~cm}$ Solar Radio Flux

o Average $10.7 \mathrm{~cm}$ Solar Radio Flux over six solar rotations

Parameters that could either be entered manually or automatically read from the system are:

o Date, year, month, and day

o Time, hour and minute

o Altitude

\section{Validation}

The model was validated by running the same test case included in reference [4]. This case is summarized in Table 1.

\section{Results}

Table 2 entails the results obtained from running NASA's MET-2 FORTRAN 77 code and DTI's SIMULINK model. The scientific formats differ between the two solution methods. Figures 1, 2, 3, and 4 illustrate the altitude change in temperature, pressure, mass density, and speed of sound, respectively. The temperature and speed of sound start to reach a plateau value at or beyond $500 \mathrm{~km}$ while the pressure and air mass density start to reach a plateau value at or beyond $50 \mathrm{~km}$. 


\section{Conclusions}

DTI's model agreed very well with the predictions of the original NASA's MET. Differences are extremely small and could be attributed to either rounding off errors or differences in accuracy between MATLAB's SIMULINK and FORTRAN 77.

We could safely claim that DTI's implementation is an honest abstraction of NASA Marshall Engineering Thermosphere.

Table 1: Parameters of the Validation Test Case

\begin{tabular}{l|r}
\hline \multicolumn{1}{c|}{ Input } & \multicolumn{1}{|c}{ Value } \\
\hline Altitude & 350.00 \\
Latitude & $45: 00$ \\
Longitude & $-120: 00$ \\
Year & 1969 \\
Month & 1 \\
Day & 20 \\
Hour & $19: 00$ \\
Minute & $11: 00$ \\
Geomagnetic Index Type & 2 \\
10.7cm Solar Flux & 136.00 \\
Average 10.7cm Solar Flux & 155.00 \\
Geomagnetic Activity Index & 9 \\
Thermodynamics Flag & 1 \\
\hline \hline
\end{tabular}

Table 2: Results of NASA's MET Code and DTI's SIMULINK Model

\begin{tabular}{l|r|r|r}
\hline \hline \multicolumn{1}{c|}{ Parameter } & $\begin{array}{c}\text { MET } \\
\text { FORTRAN 77 } \\
\text { CODE }\end{array}$ & $\begin{array}{c}\text { DTI's Simulink } \\
\text { Model }\end{array}$ & Units \\
\hline Exospheric temperature & 1031.207 & 1031.231 & $\mathrm{~K}$ \\
Temperature & 1019.849 & 1019.873 & $\mathrm{~K}$ \\
N2 number density & $0.3289 \mathrm{E}+14$ & $3.2898 \mathrm{E}+13$ & $/ \mathrm{m}^{3}$ \\
O2 number density & $0.1660 \mathrm{E}+13$ & $1.6598 \mathrm{E}+12$ & $/ \mathrm{m}^{3}$ \\
O number density & $0.2811 \mathrm{E}+15$ & $2.8114 \mathrm{E}+14$ & $/ \mathrm{m}^{3}$ \\
A number density & $0.5398 \mathrm{E}+10$ & $5.3995 \mathrm{E}+09$ & $/ \mathrm{m}^{3}$ \\
He number density & $0.5449 \mathrm{E}+13$ & $5.4486 \mathrm{E}+12$ & $/ \mathrm{m}^{3}$ \\
H number density & $0.1000 \mathrm{E}+07$ & $1.0000 \mathrm{E}+06$ & $/ \mathrm{m}^{3}$ \\
Average molecular wt. & 17.110 & 17.1096 & $\mathrm{~kg} / \mathrm{m}^{3}$ \\
Total mass density & $0.9123 \mathrm{E}-11$ & $9.1237 \mathrm{E}-12$ & \\
Log10 mass density & -11.040 & -11.0398 & $\mathrm{~Pa}^{3}$ \\
Total pressure & $0.4521 \mathrm{E}-05$ & $4.5217 \mathrm{E}-06$ & $\mathrm{~m} . \mathrm{sec}^{-2}$ \\
Local gravity acceleration. & 8.80982 & 8.0809815 & 1 \\
Ratio specific heats & 1.64095 & 1.640946 & $\mathrm{~m}$ \\
Pressure scale-height & 56254.6 & 56255.58 & $\mathrm{~m}^{2} . \mathrm{sec}^{2} . \mathrm{K}^{-1}$ \\
Specific heat const. Pressure & 1244.11 & 1244.1098 & $\mathrm{~m}^{2} . \mathrm{sec}^{2} . \mathrm{K}^{-1}$ \\
Specific heat const. Volume & 758.168 & 758.1658 & \\
\hline \hline
\end{tabular}




\section{References:}

[1] "U.S. Standard Atmosphere 1976," U.S. Government Printing Office, Washington, D.C., 1976.

[2] “U.S. Standard Atmosphere 1976," http://www.pdas.com/refs/us76.pdf

[3] "Properties Of The U.S. Standard Atmosphere 1976," http://www.pdas.com/atmos.htm

[4] Owens, J. K., "NASA Marshall Engineering Thermosphere Model - Version 2.0," NASA TM-211786, Washington, DC, 2002.

[5] Hickey, M. P., "The NASA Engineering Thermosphere Model," NASA CR-179359, Washington, D.C., 1988.

[6] Hickey, M. P., "An Improvement in the Integration Procedure Used in the Marshall Engineering Thermosphere Model," NASA CR-179389, Washington, D.C., 1988.

[7] Justus, C. G. and Johnson, D. L., "The NASA/MSFC Global Reference Atmospheric Model - 1999 Version (GRAM-99)," NASA TM-209630, Washington, D.C., 1999.

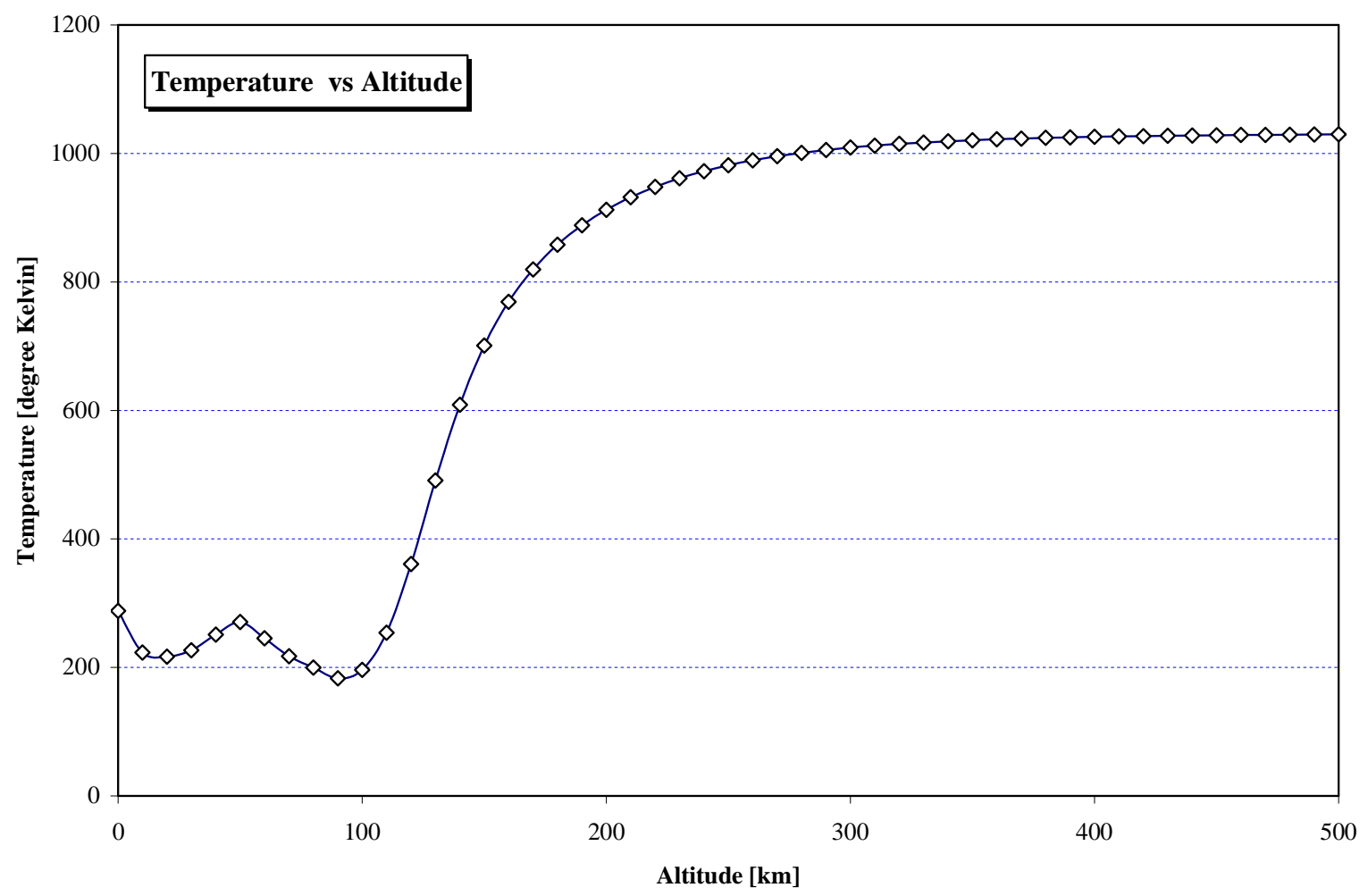

Figure 1: Temperature vs. Altitude (up to 500km) 


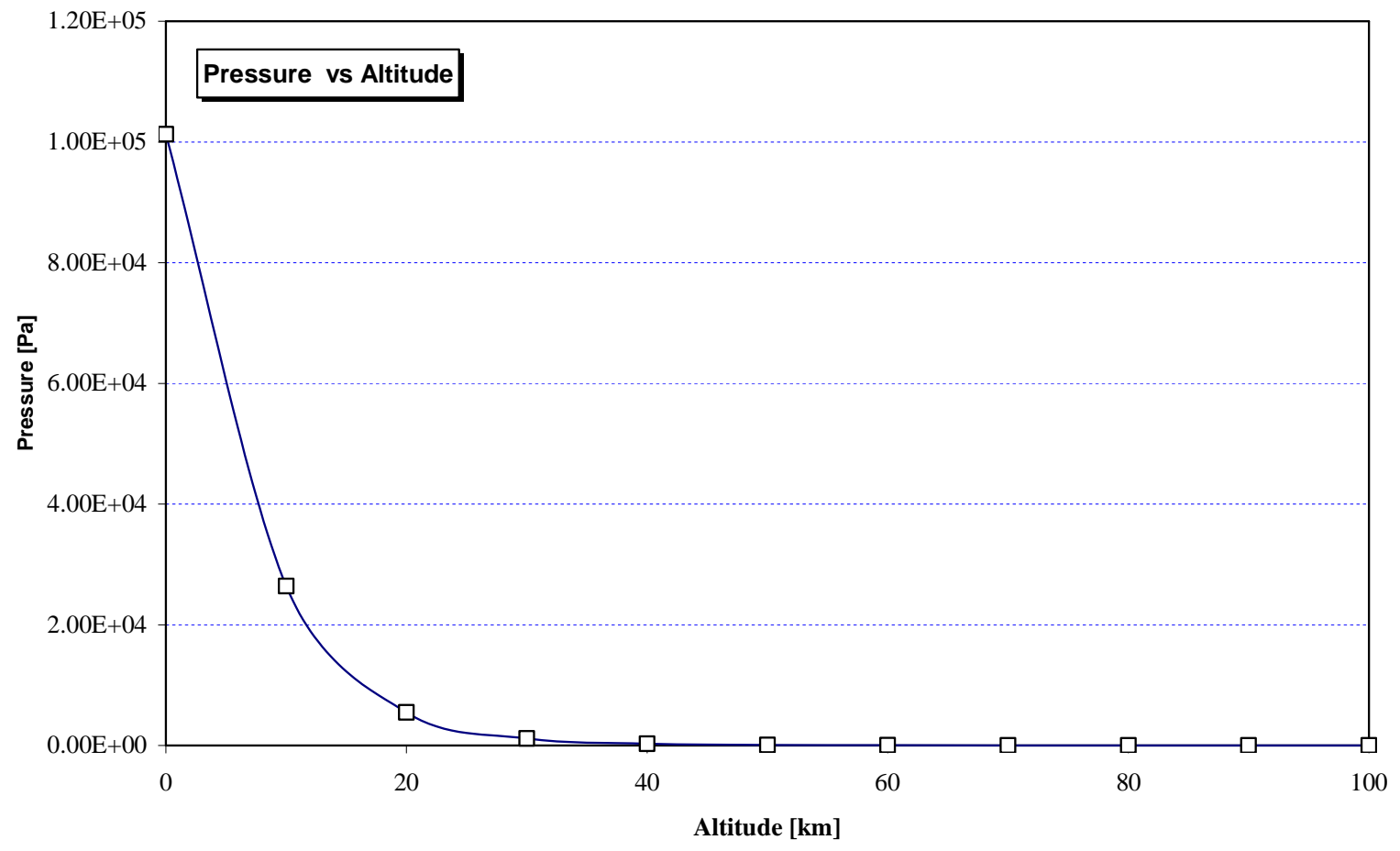

Figure 2: Atmospheric Pressure vs. Altitude (up to $100 \mathrm{~km}$ ) 


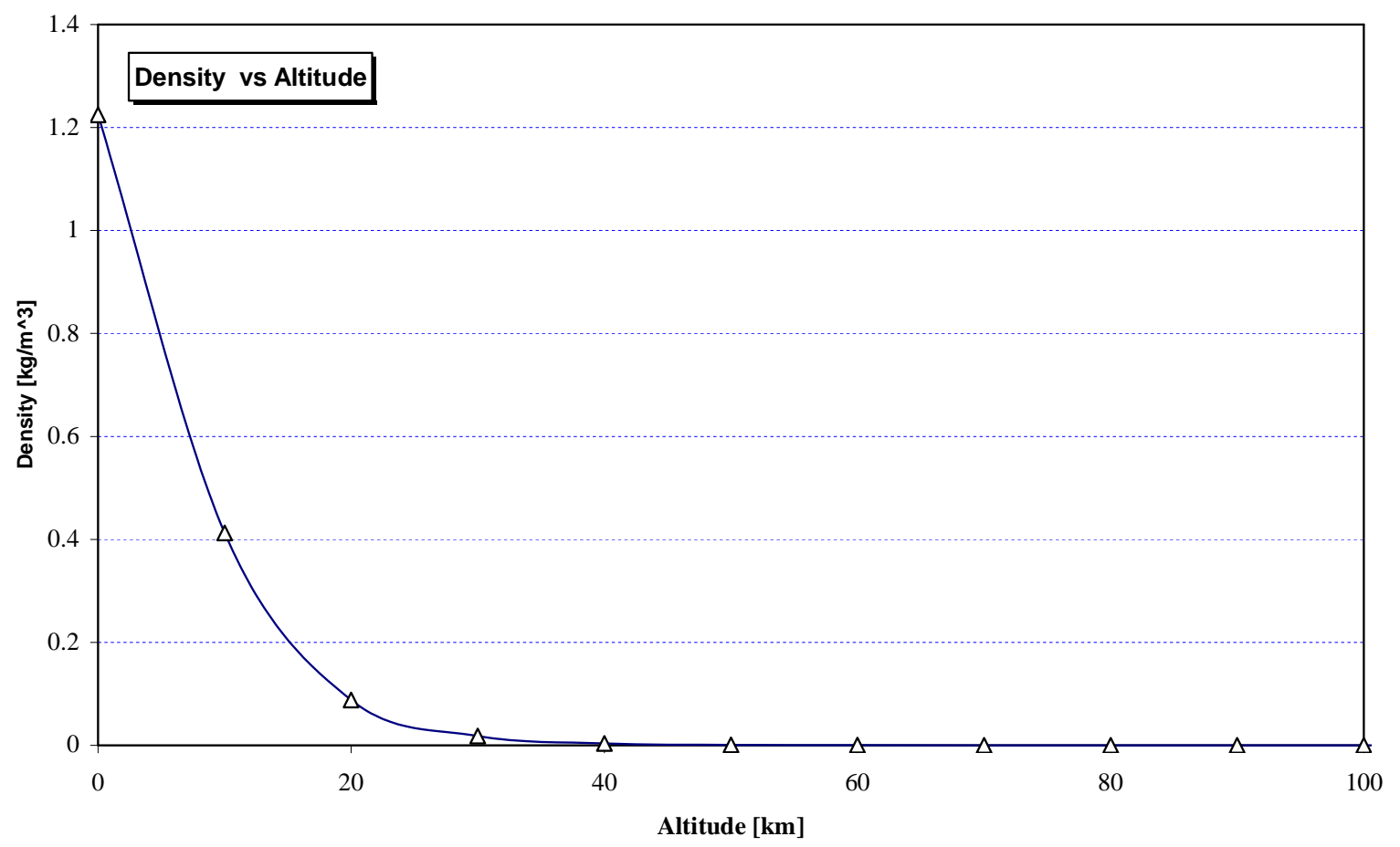

Figure 3: Air Mass Density vs. Altitude (up to 100km)

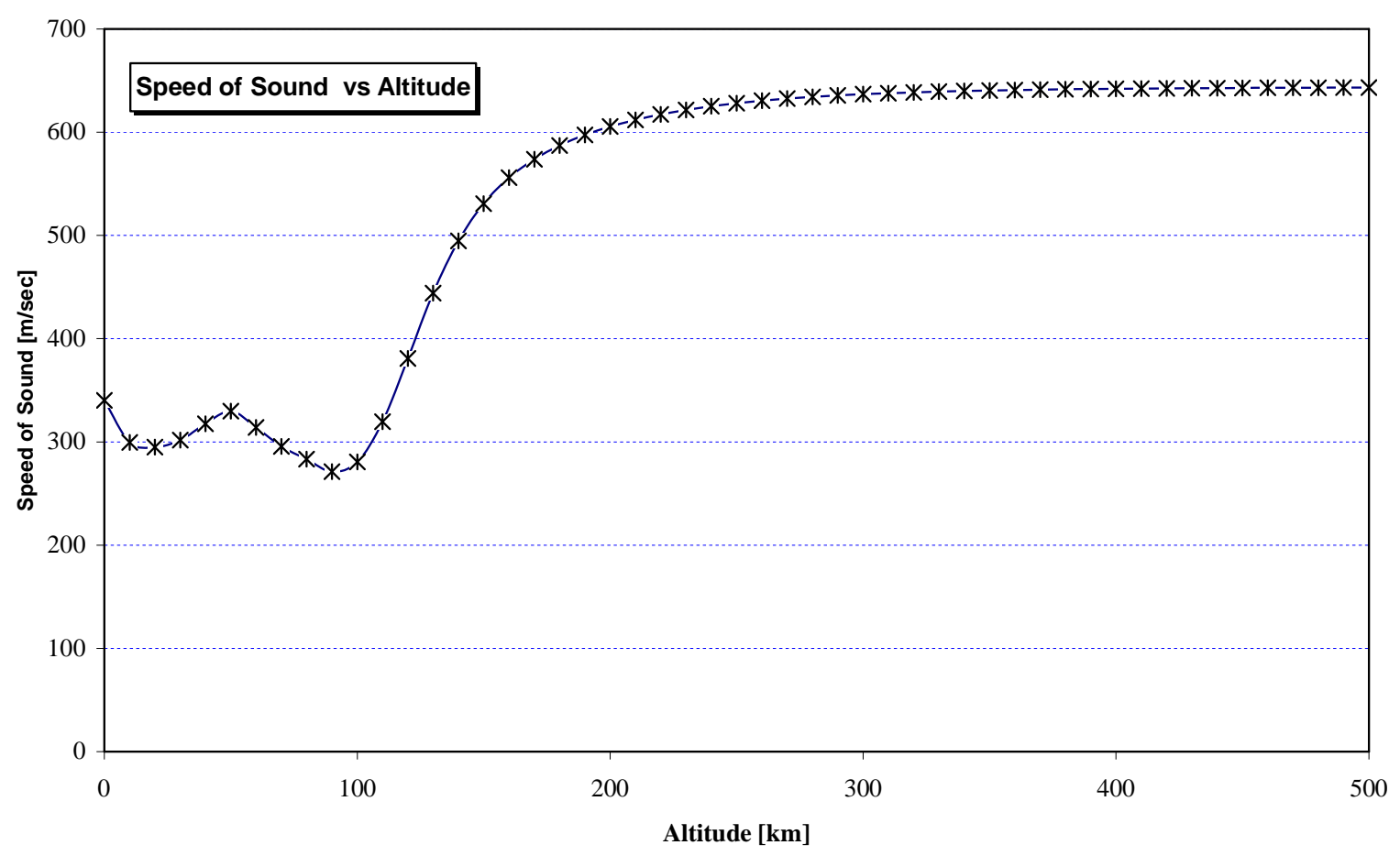

Figure 4: Speed of Sound vs. Altitude (up to 500km) 


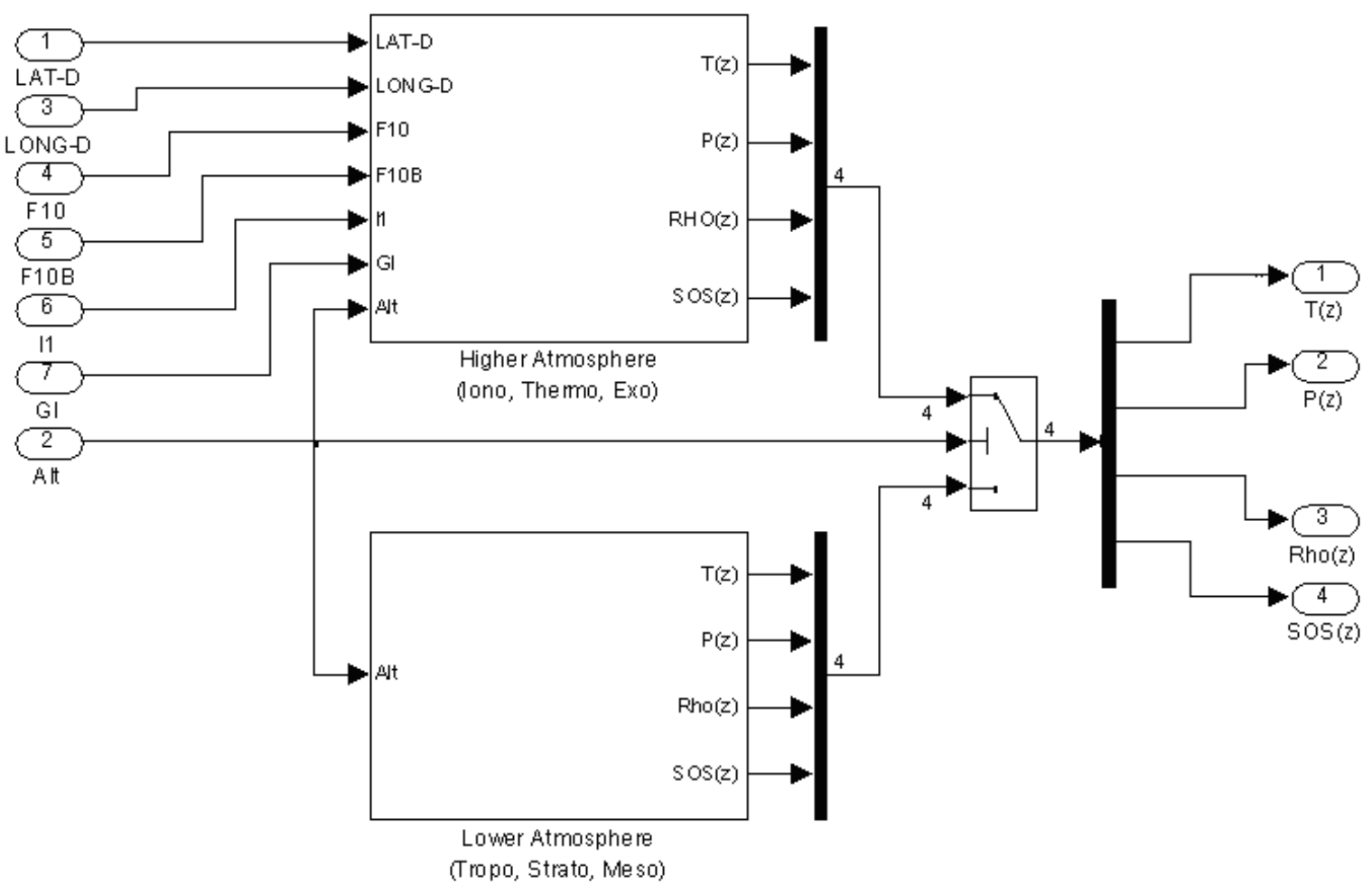

This subsystem computes the parameters of both the Hlgher and Lower Atmosphere and selects the output based on Altitude

Figure 5: Integration of NASA Marshall Engineering Thermosphere with the US Standard Atmosphere 1976

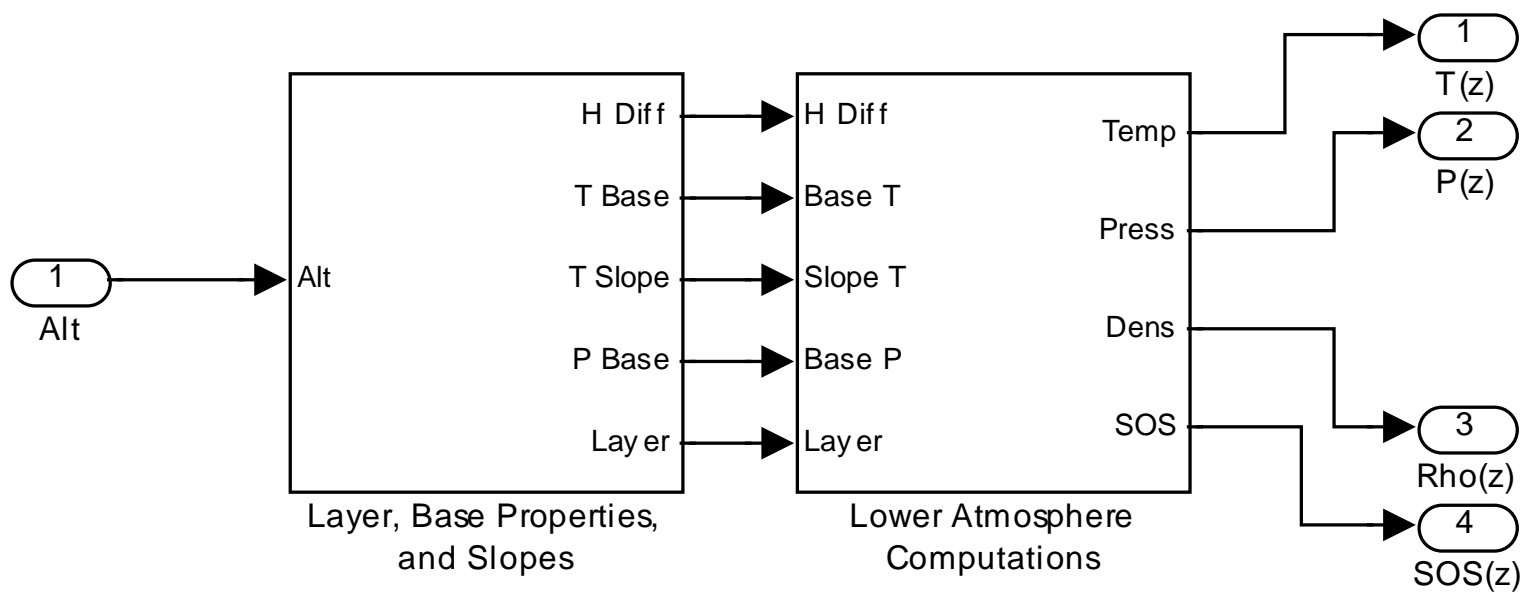

This subsystem computes the parameters of lower atmosphere $(0-90 \mathrm{~km})$ based on current altitude

Figure 6: General Layout of the U.S. Standard Atmosphere 1976 

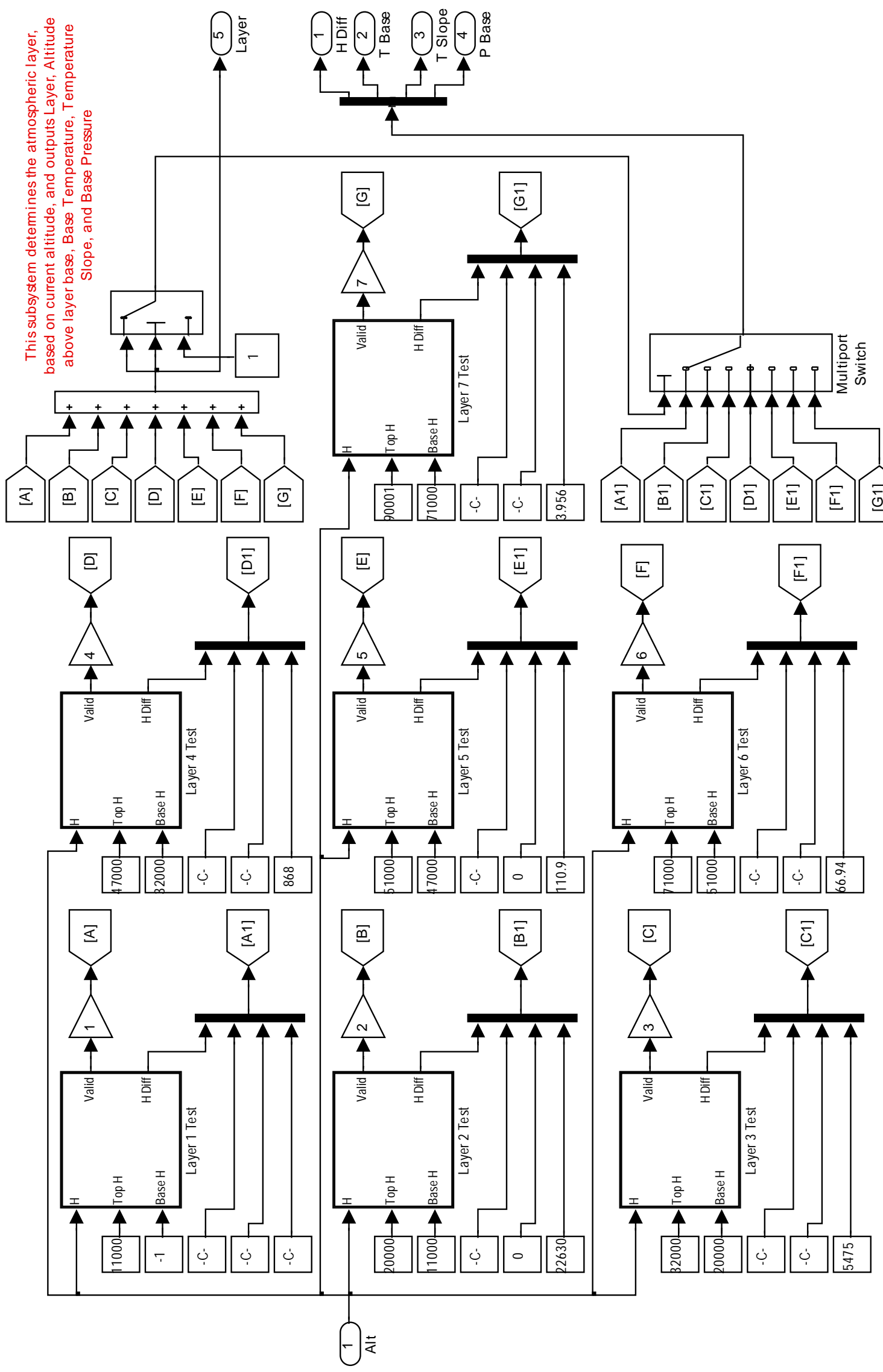

Figure 7: Layers, Base Properties, and Slopes of the U.S. Standard Atmosphere 1976 


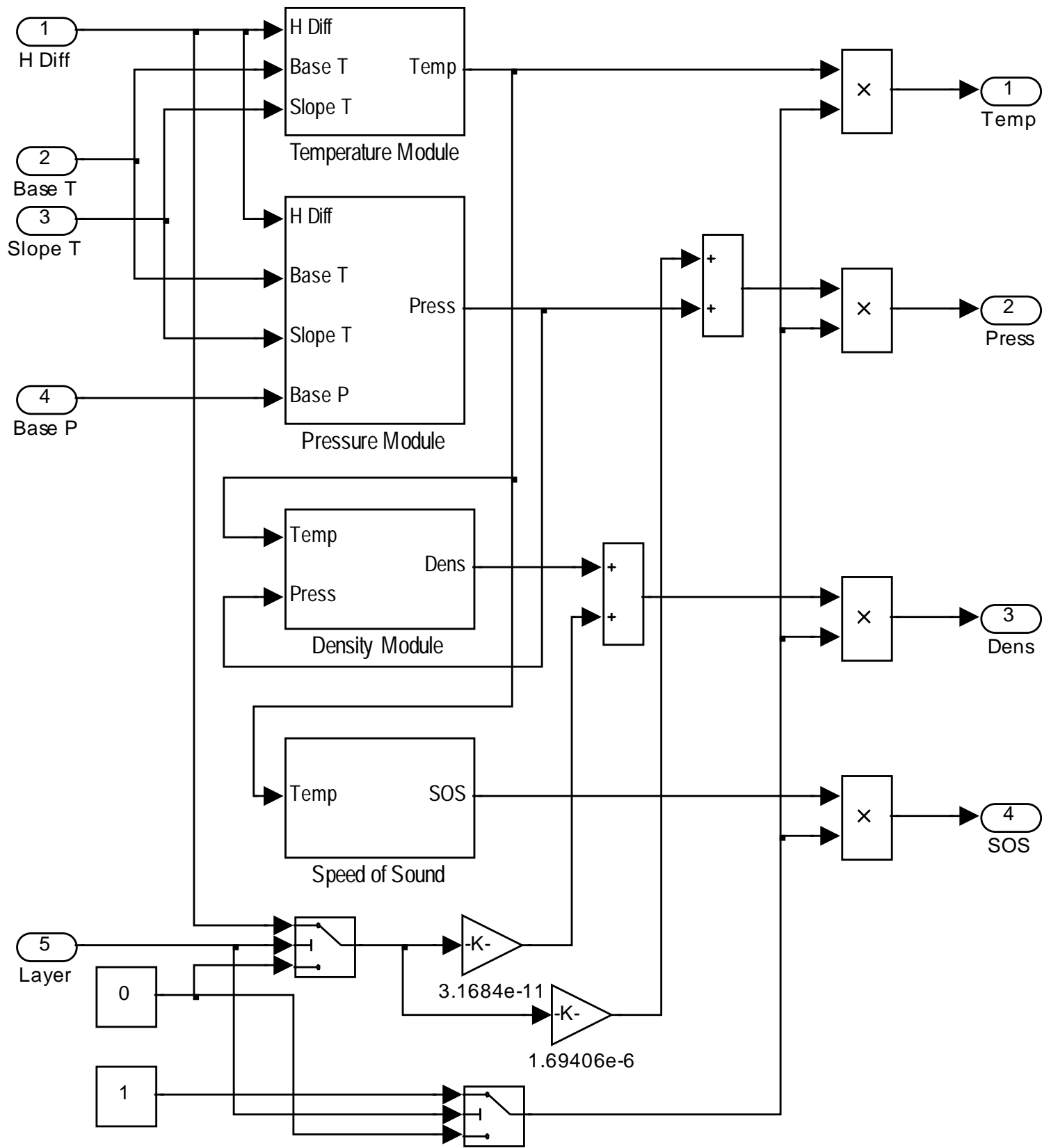

This subsystem computes the Temperature, Pressure, Density, and Speed of Sound corresponding to current altitude

Figure 8: Computation Modules of the Properties of the U.S. Standard Atmosphere 1976 


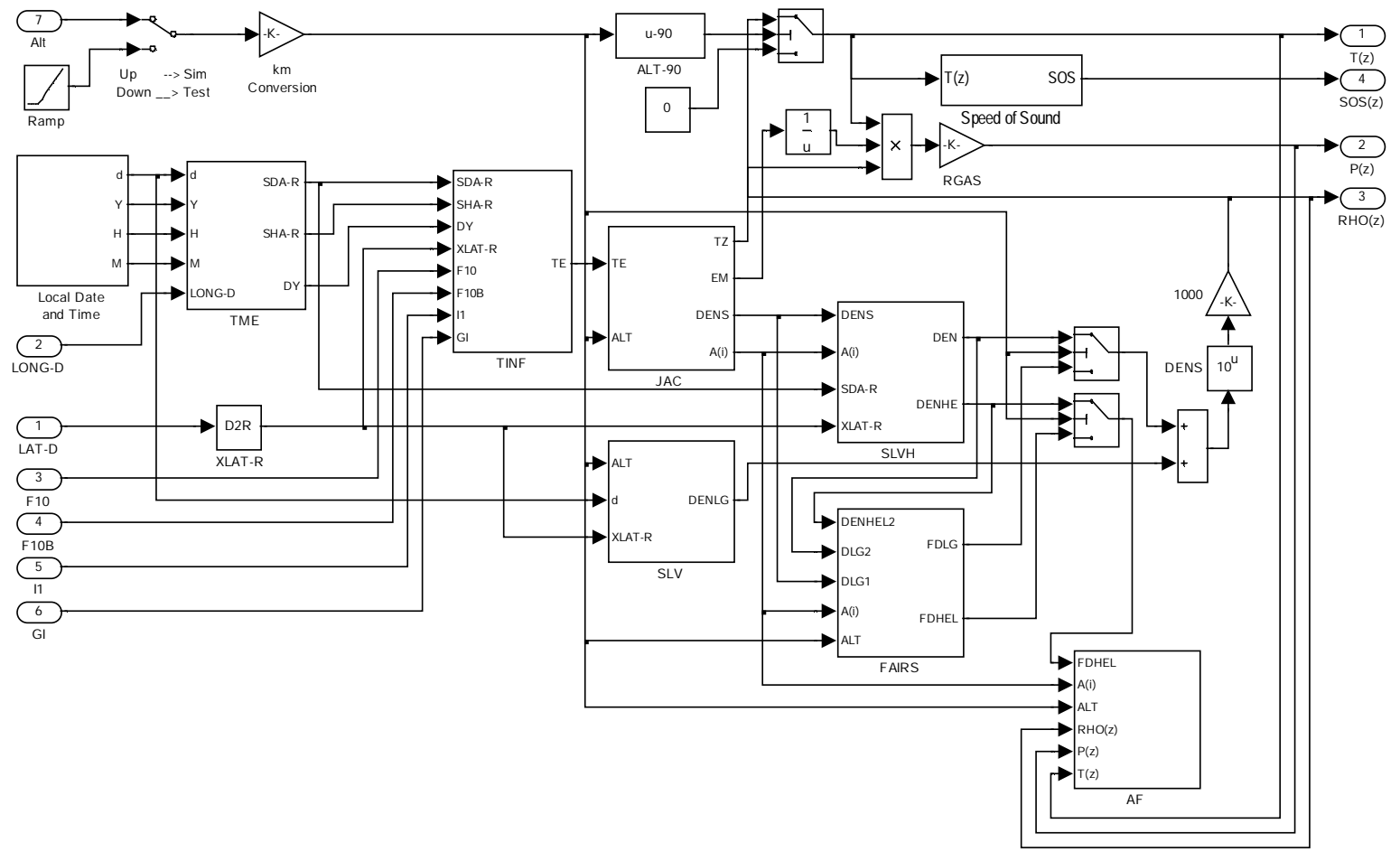

Figure 9: Elements of NASA Marshall Engineering Thermosphere

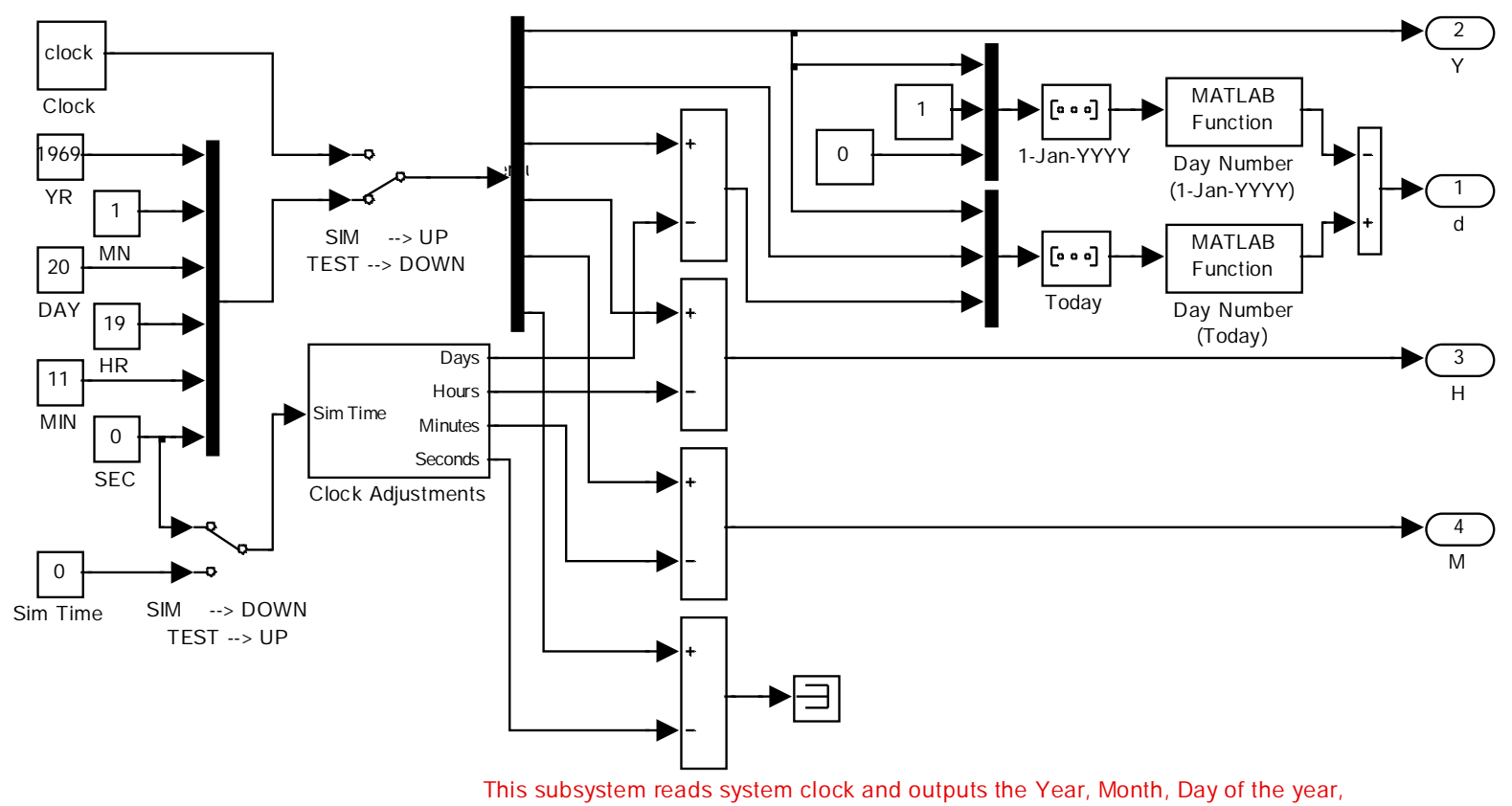
Hour, and Minutes at the start of Simulation

Figure 10: Local Date and Time Module 


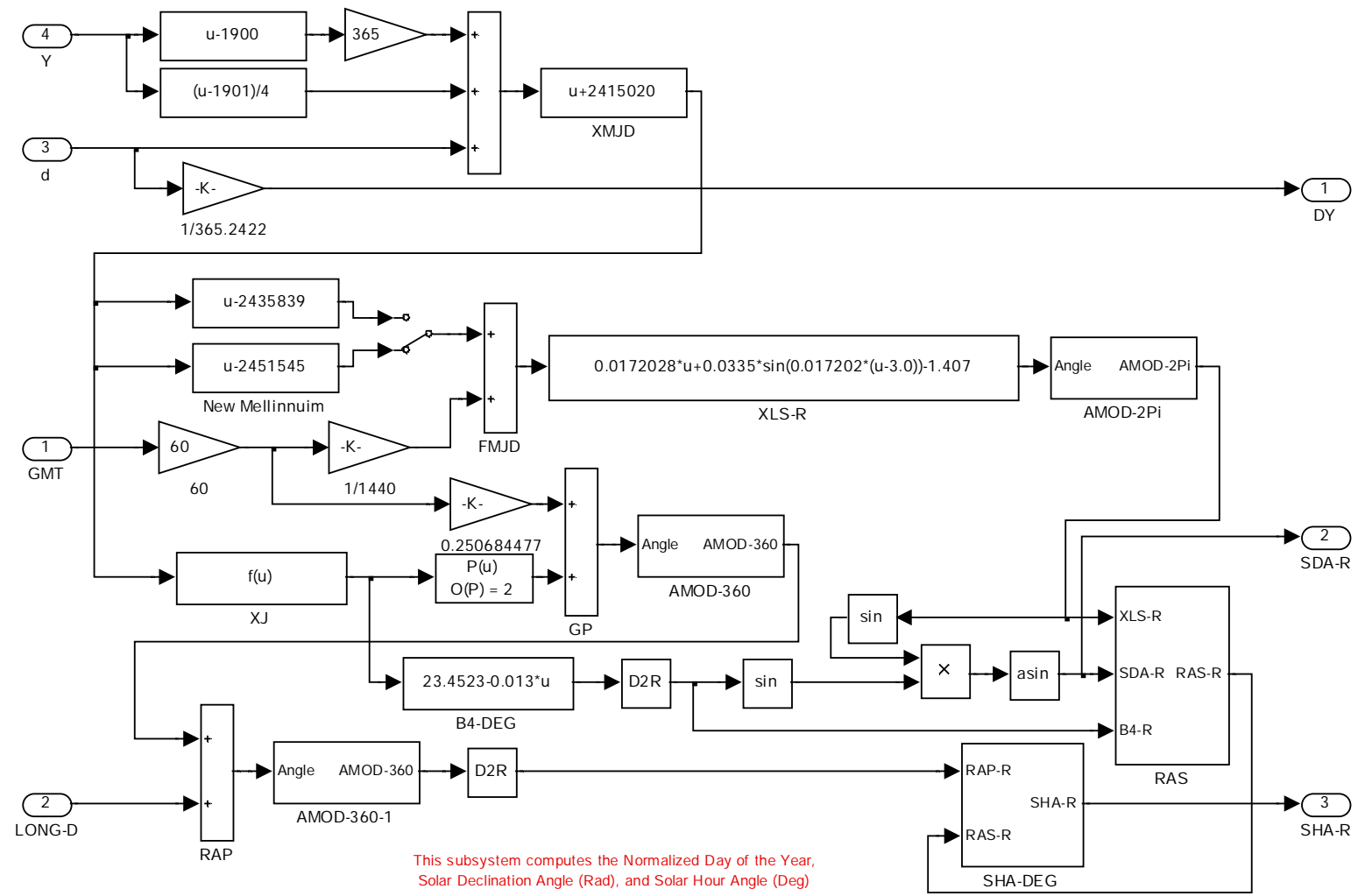

Figure 11: TME subsystem that computes Solar Positions

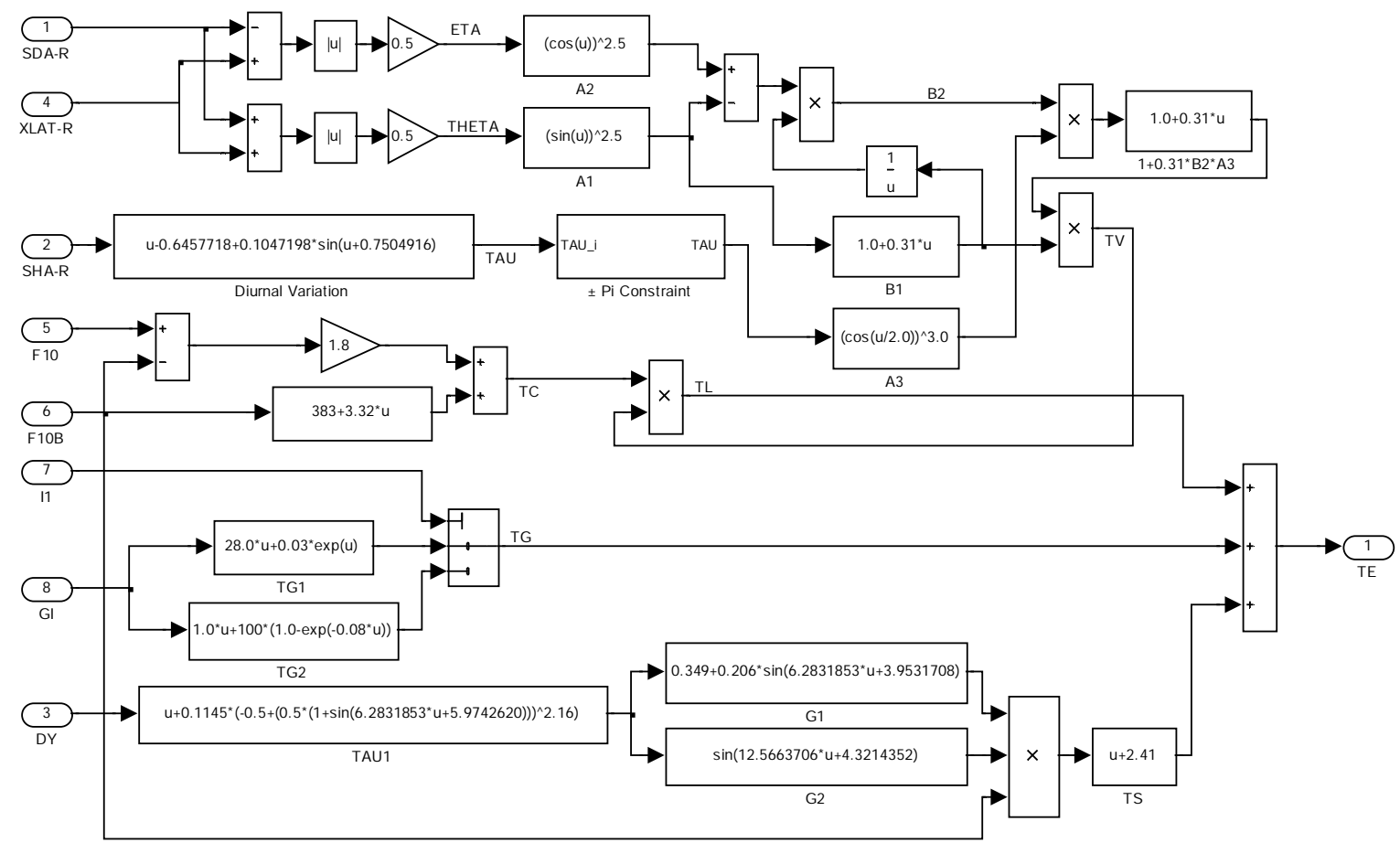

This subsystem computes the Temperature ( ${ }^{\circ} \mathrm{K}$ ) of the Thermosphere

Figure 12: The TINF module that computes the Exospheric Temperature (TE) 


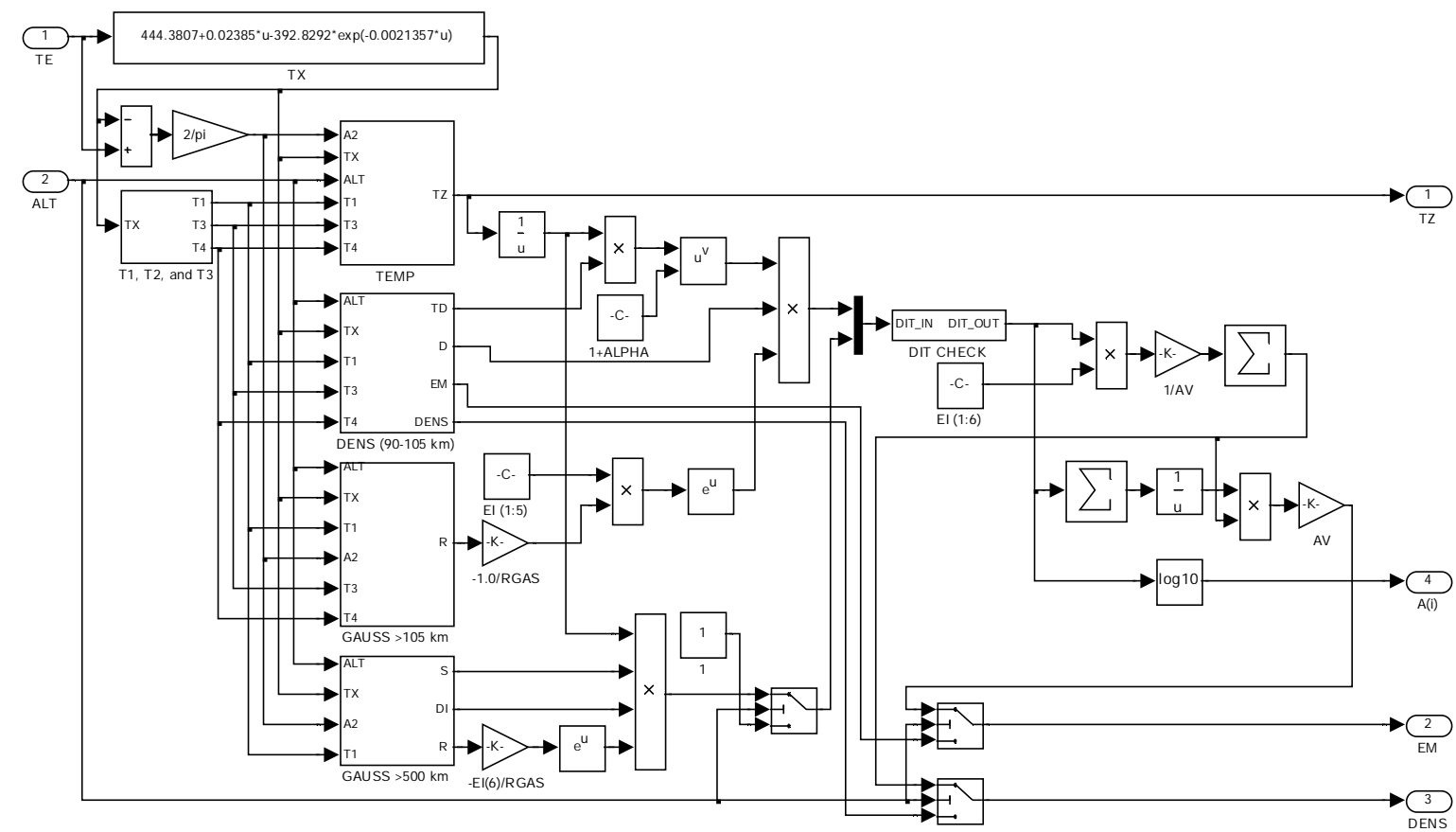

This subusystem computes the Density, Mean Molecular Weight, and Individaul Specie Number Density

Figure 13: The JAC module that computes Temperature (TZ), Mean Molecular Weight (EM), Density (DENS), and the Individual Specie Number Density (A(i)) at any given altitude

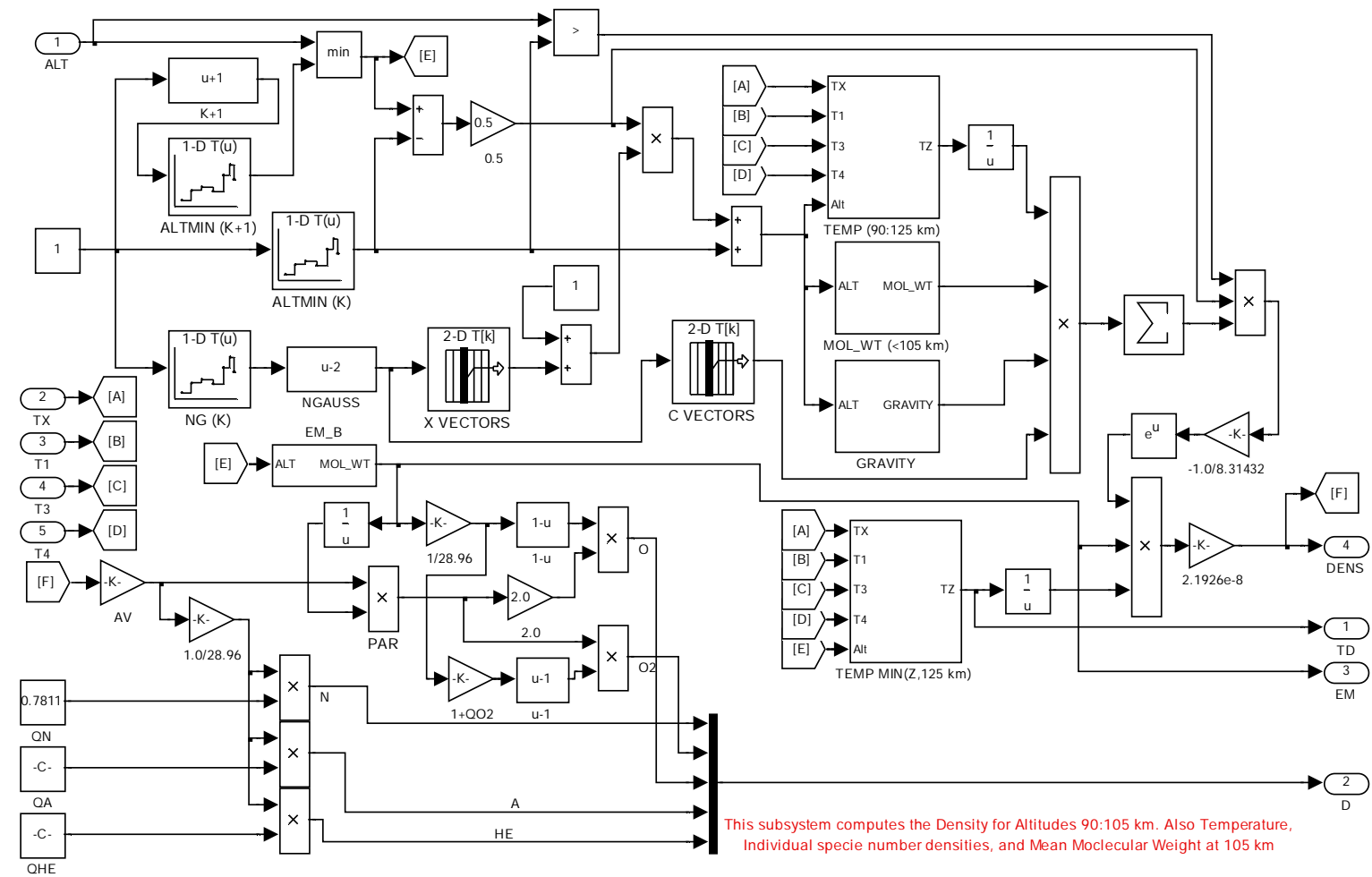

Figure 14: The JAC subsystem that computes Density (DENS) and Mean Molecular Weight (EM) in the range $90-105 \mathrm{~km}$. It also computes the Temperature (T0) and the Individual Specie Number Density (D) at $105 \mathrm{~km}$ 


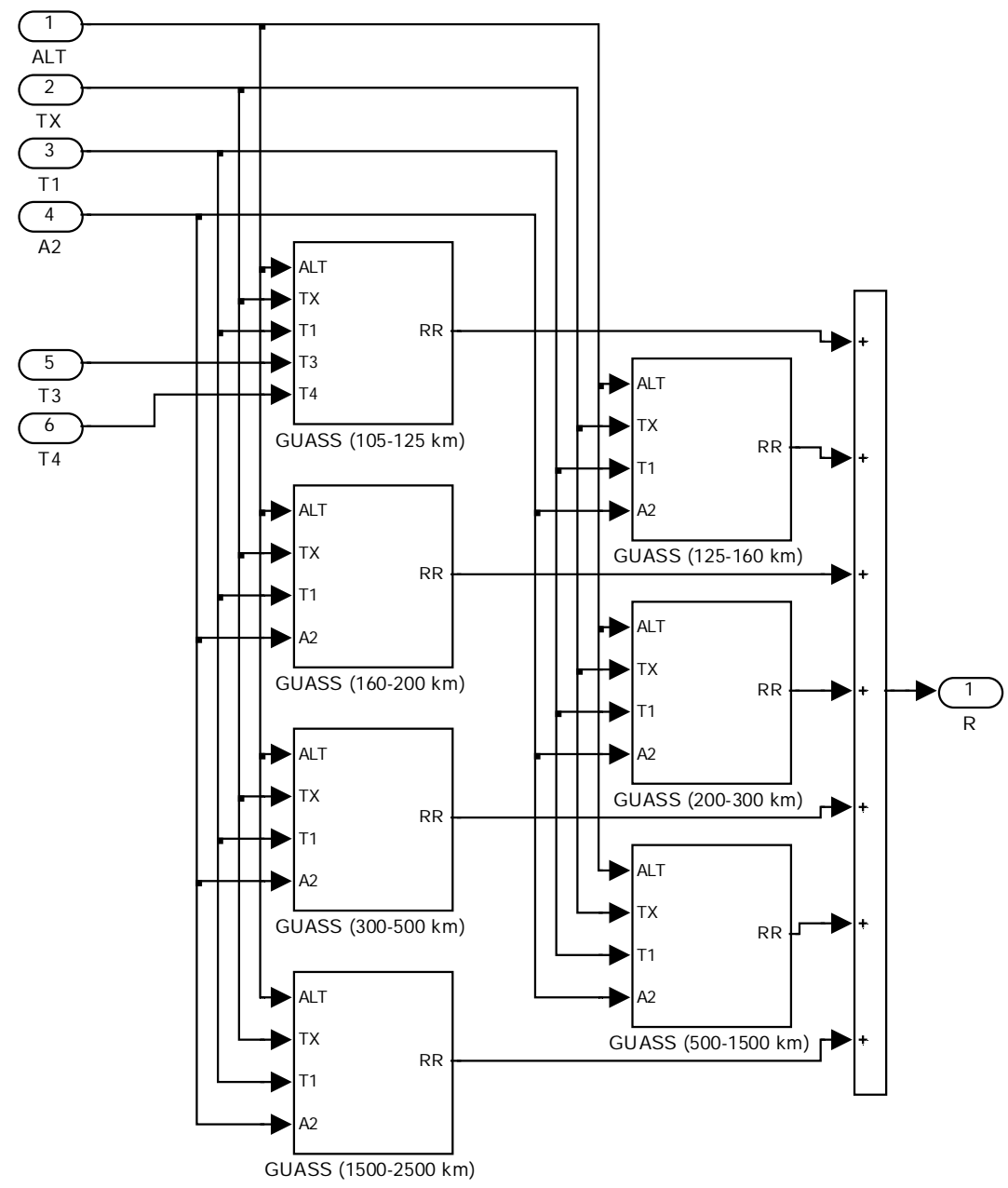

Figure 15: The JAC subsystem that implements Gaussian Quadrature in the range $105-2500 \mathrm{~km}$

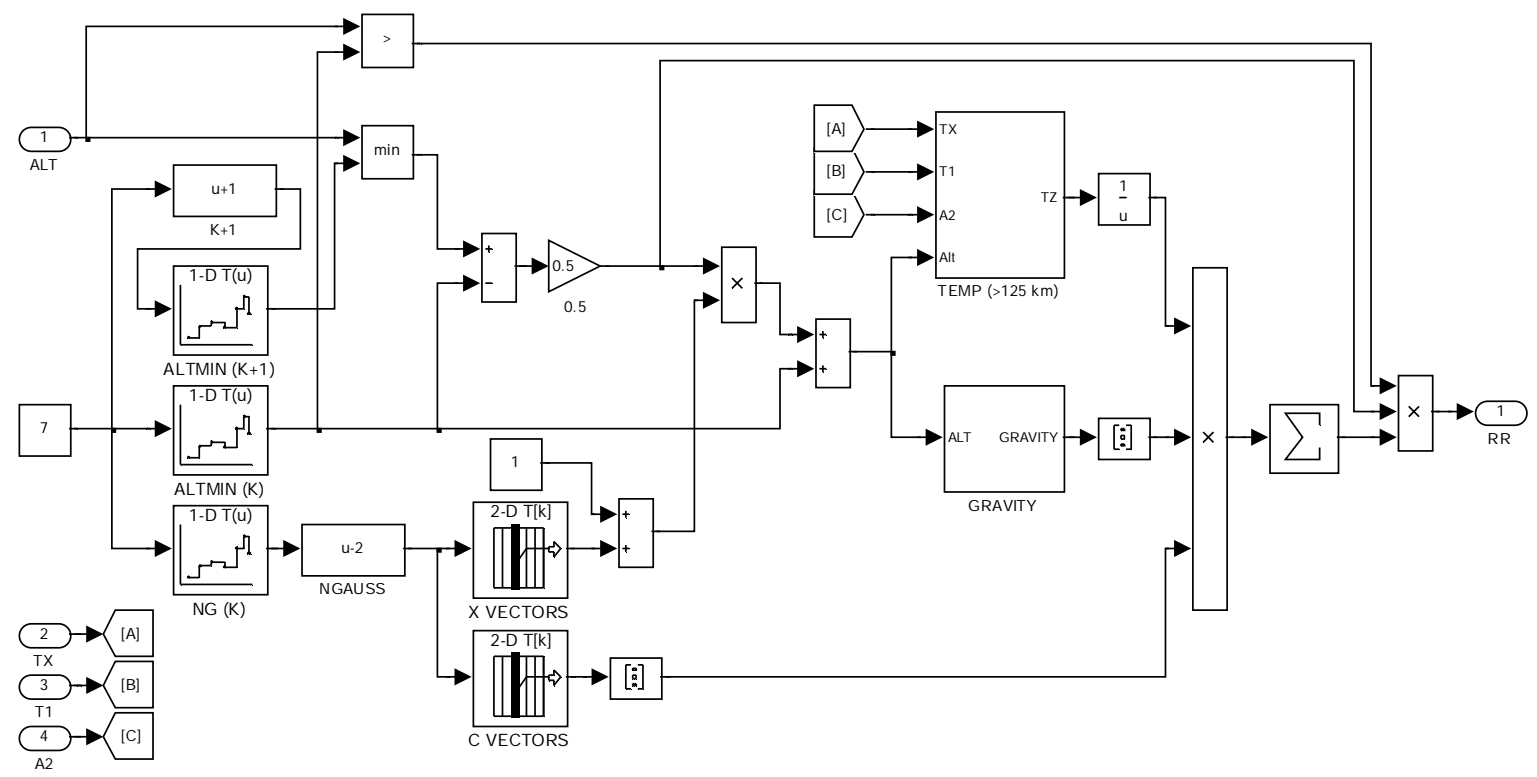

This subsystem computes the Density for Altitudes 500:1500 km

Figure 16: The JAC subsystem that implements Gaussian Quadrature sublayer in the range $105-2500 \mathrm{~km}$ 


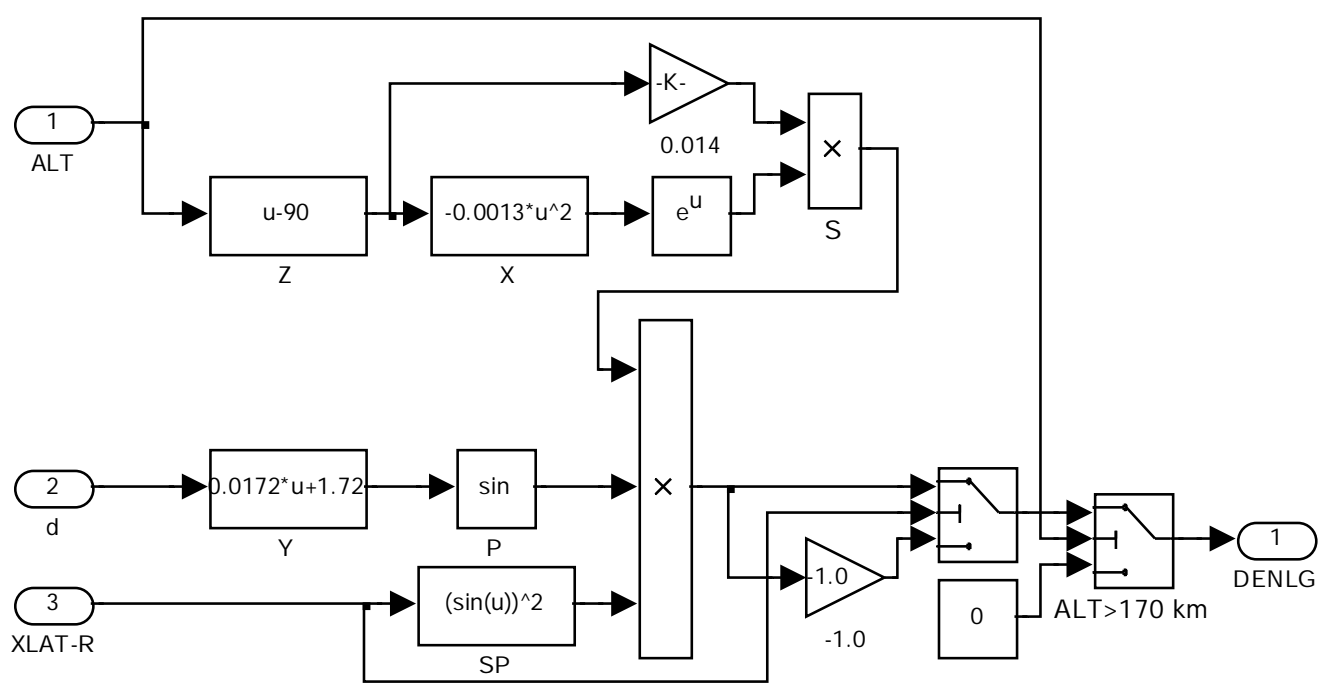

This block computes the Seasonal-Latitudinal Variation of Density for altitudes $<170 \mathrm{~km}$

Figure 17: The SLV module that computes Seasonal-Latitudinal Variations in Density below $170 \mathrm{~km}$

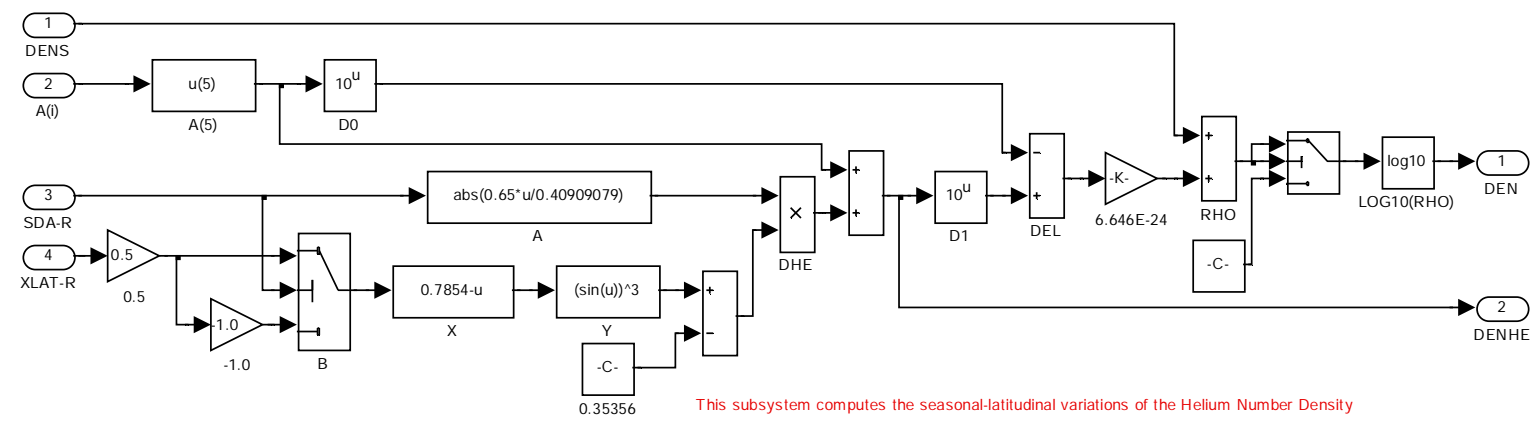

Figure 18: The SLVH module that computes Seasonal-Latitudinal Variations in Helium Density above $170 \mathrm{~km}$

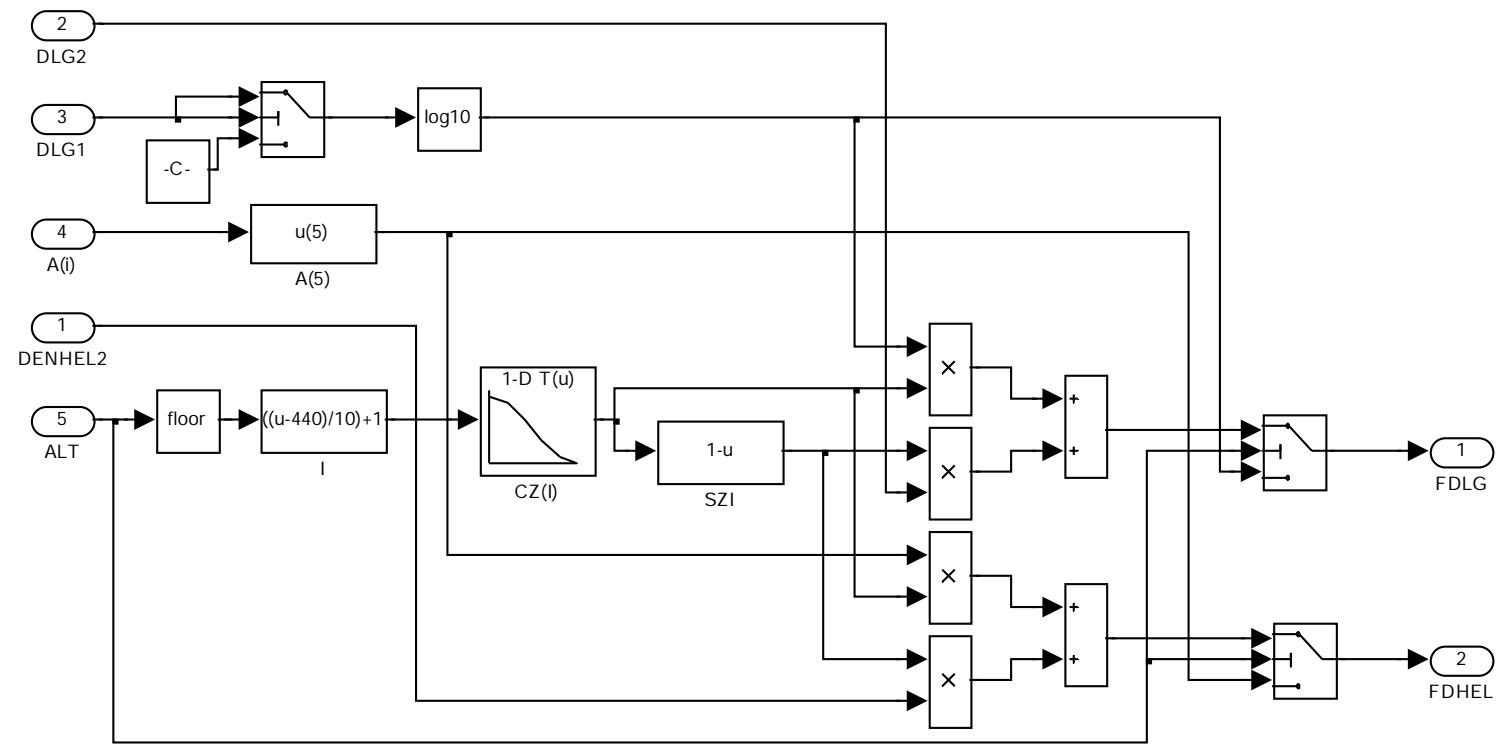

This subsystem Fairs total and helim densities between 440:500 km

Figure 19: The Fairs module that ensures smooth transition of Total and Helium Densities in the range 440-500km 


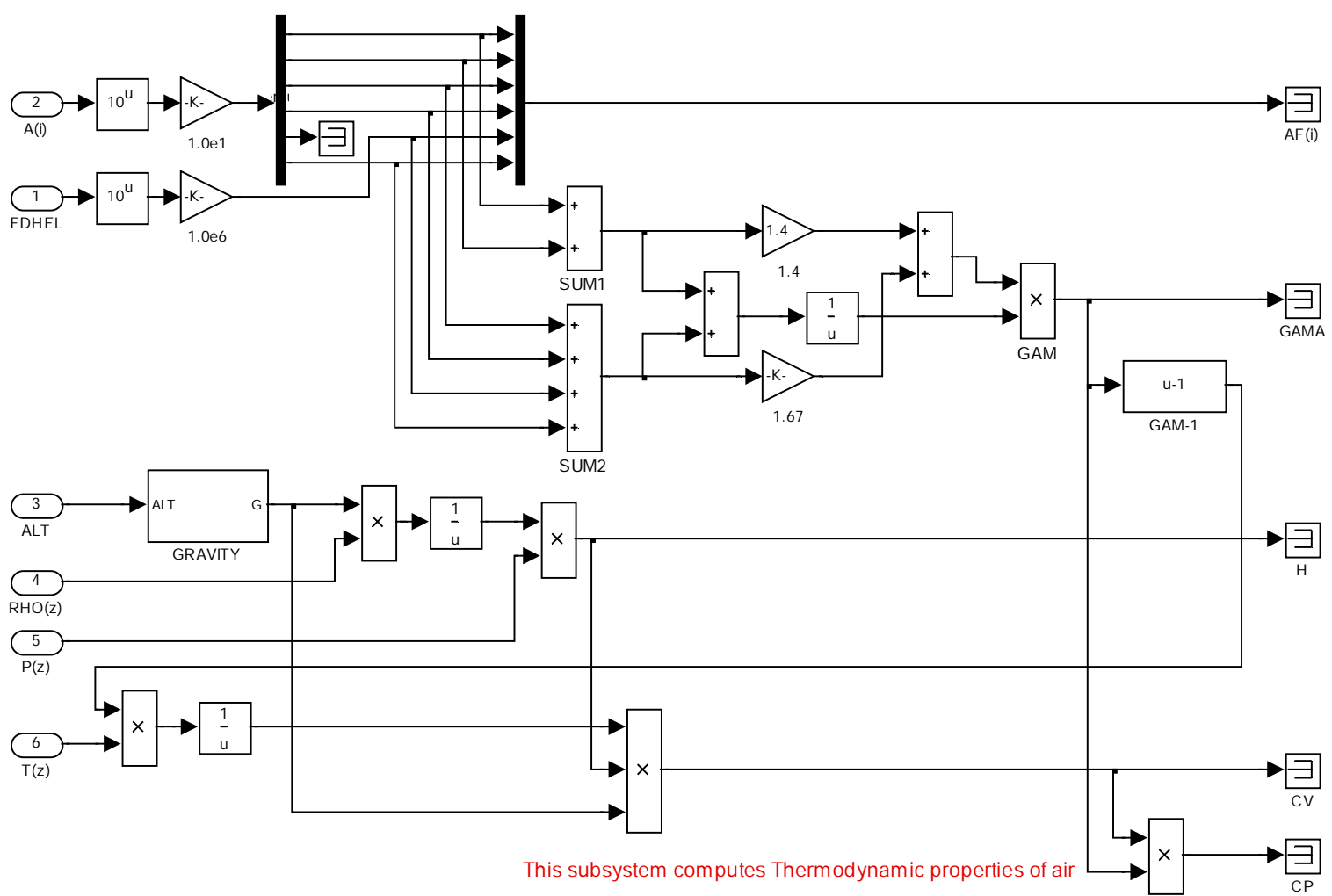

Figure 20: The AF module that computes Specific Heats and their Ratio

(CV, CP, GAMA), the Pressure Scale Height (H), and the Individual Specie Number Density (AF) 